\title{
Autobiografia como instrumento no processo identitário do docente: uma reflexão sobre vivências no PIBID
}

\author{
Autobiography as a constitutive instrument \\ in teacher identity: a reflection on experiences in PIBID
}

Jenifer Jully Vilela de Oliveira ${ }^{1}$

\section{Resumo}

Muito tem-se discutido acerca da importância do Programa Institucional de Bolsas de Iniciação à Docência, PIBID para a formação de professores, já que ele pretende promover a iniciação do licenciando no ambiente escolar da rede pública de ensino, além de aproximar o aluno com a prática docente (NÓVOA, 2013; ROMERO, 2017). Pensando nisso, por meio de uma autobiografia, abordo como o programa auxiliou em minha formação e as experiências que possibilitaram a construção e reflexão de minha identidade docente, enfatizando o meu desenvolvimento durante o período de licenciatura, uma vez que a prática docente está em consonância com a formação da identidade do indivíduo (HALL, 2006; BARCELOS, 2016). Nesse viés, Zabalza (2004), Nóvoa (2013), Barcelos (2016), asseveram que o professor se constrói a partir das experiências de acordo com o contexto em que ele se encontra e não somente embasado nos conteúdos propostos em cursos de formação. Inserindo-me nessa vertente de pesquisa, analiso como eu, estudante de Letras, avalio minha participação no PIBID, minhas contribuições participando no programa e dificuldades durante o trabalho. Além disso, analiso, por meio da Linguística Sistêmico Funcional (WHITE E MARTIN, 2005) como signifiquei minhas experiências e desafios de acordo com o subsistema de atitude. Com a elaboração e análise da autobiografia pude perceber que a reflexão acerca da minha prática docente permitiu que eu ressignificasse minhas ações, transformasse minhas concepções sobre ensino-aprendizagem, percebesse e valorizasse a ajuda do outro, além de evidenciarem quanto o PIBID influenciou na minha identidade docente.

Palavras-chave: PIBID; narrativas autobiográficas; formação docente.

\begin{abstract}
Much has been discussed about the importance of the Programa Institucional de Bolsas de Iniciação à Docência, PIBID, as well as about the contribution that such program offers to teacher, since it intends to promote the initiation of the undergraduate in the school environment of the education network in addition to bringing the student closer to teaching practice (NÓVOA, 2013; ROMERO, 2017). Thinking about this, I intend, through an autobiography, how the program helped in my training and the experiences that made the
\end{abstract}

1.Mestre em Educação; Universidade Federal de Lavras, Lavras/MG, Brasil, e-mail: jenisvilela@gmail.com; 
construction and reflection of my teaching identity possible, taking into account my development as a undergraduate, since the teaching practice is aligned with the formation of the individual's identity (HALL, 2006; BARCELOS, 2016). In this bias, Zabalza (2004), Nóvoa (2013), Barcelos (2016), assert that the teacher is constructed from the experiences according to the context in which he is and not only based on the contents proposed in training courses. Inserting myself in this research area, I analyze how I, as a Letter's student, evaluate my participation on PIBID, my contributions during the participation in the program and difficulties during the work. I analyze, through Functional Systemic Linguistics (WHITE AND MARTIN, 2005), how my experiences and challenges mean according to the attitude subsystem. With the elaboration and analysis of the autobiography I could see that the reflection about my teaching practice allowed me to reframe my actions, transform my conceptions about teaching-learning, perceive and value the help of others, in addition to showing how much PIBID influenced my identity teacher.

Keywords: PIBID; autobiographical narratives; teacher training.

\section{Introdução}

Muitos são os caminhos que nos levam a construir e ressignificar nossa identidade. As experiências que marcam nossas vidas, principalmente as que envolvem emoção (BARCELOS, 2016), bem como as pessoas com quem interagimos em nossa trajetória, nos constroem e reconstroem a cada dia. Nesse sentido, estudar a identidade docente é buscar compreender os sujeitos face a essa era em que estamos inseridos, aos sistemas e às burocracias cotidianas, que, por vezes, nos mecanizam ao ponto de não refletirmos mais sobre nossas ações e sobre quem somos (SOUZA, 2016). Assim, especificamente no que concerne a identidade docente, Gatti e Barreto (2009) consideram uma postura positiva ouvir os professores em meio a esse atual contexto.

É importante destacar, nesta pesquisa, a relevância do trabalho com narrativas autobiográficas, tendo em vista que elas buscam compreender a identidade do indivíduo, já que elas podem mapear a forma de atuação do professor no mundo e permitem identificar fatos e pessoas de sua história que possam ter influenciado o trabalho pedagógico que realiza. Tal compreensão é relevante para estudos do processo de formação porque a identidade profissional não é dada, mas construída em todas as relações (FREUDENBERGER E PEREIRA, 2012; SOUZA, 2011, 2016; BARCELOS, 2016; BLOCK, 2017), e que, muitas vezes, pode se perder no cotidiano árduo no qual o docente se insere, não lhe permitindo 
mudanças em sua prática, por, geralmente, considerar o trabalho com narrativas um privilégio do qual ele não pode desfrutar.

Ademais, vale apontar que o professor não se constitui somente a partir de conceitos cognitivos ou de conteúdos preestabelecidos, mas das vivências e dos significados que ele constrói em decorrência das interações realizadas durante o processo formativo (GATTI, 2013, NÓVOA, 2013; BARCELOS, 2016). Ou seja, as interações e relações que temos uns com os outros, seja com professor, colega ou até mesmo pessoas fora do contexto escolar, afetam nossa formação, pois, em consonância com a perspectiva Vygotskiana (1995), aprendemos com diferentes meios e grupos sociais com os quais interagimos.

Dessa forma, especificamente neste estudo, destaco como o Programa Institucional de Bolsa de Iniciação à Docência - PIBID - contribuiu para o desenvolvimento de minha identidade docente (BARCELOS, 2016; BLOCK, 2017; ROMERO, 2017; REICHMANN E ROMERO, 2019). E, para isso, tenho como objetivo geral analisar, por meio de narrativa autobiográfica, de que forma o programa auxiliou na formação de minha identidade docente como professora de Português, norteada pelas perguntas de pesquisa: a) Quais os pontos de minha experiência formativa no PIBID considerei mais relevantes?; b) Quais os desafios encontrados durante minha participação no PIBID?; c) Como signifiquei minhas experiências e desafios de acordo com o subsistema de atitude (julgamento, afeto e apreciação)?

As duas primeiras perguntas de pesquisa são respondidas com a identificação em minha narrativa dos respectivos momentos, seguidos de considerações ancoradas na literatura da área, como o conceito de identidade, formação docente e narrativas autobiográficas. A terceira pergunta, respondo embasada na teoria da Linguística Sistêmico Funcional, no subsistema de atitude.

Para subsidiar minhas discussões, inicio por explicitar o contexto de produção, ou seja, o PIBID como realizado no país e especificamente no projeto do qual fiz parte. A seguir, discuto conceitos de identidade, formação docente do professor de português, narrativas autobiográficas e o sistema de Avaliatividade, levando em consideração que, além de interpretar os dados, também os analisei linguisticamente para adentrar nos significados construídos por meio da linguagem. Na sequência, explicito a metodologia por meio da qual analisei a pesquisa, caracterizada como qualitativa e interpretativa. Discuto, então, os dados, dando ênfase às perguntas de pesquisa previamente estabelecidas. Por fim, teço considerações sobre o estudo realizado. 


\section{Contextualização}

Antes de iniciar o quadro teórico, cabe apontar o contexto de produção em que foi desenvolvida minha narrativa autobiográfica, bem como explicar o que é o PIBID e como ele funciona, além das características do projeto em que me inseri na instituição da qual fiz parte durante minha graduação.

Logo no segundo período do curso de Letras na universidade, comecei a participar do PIBID de Português. O grupo de alunos que participavam desse PIBID era dividido para atuar em 4 escolas, cada uma com um professor/supervisor. $\mathrm{O}$ objetivo era inserir o estudante da graduação no ambiente escolar da rede pública para aprimorar sua prática. Além disso, o coordenador do PIBID de Língua Portuguesa na universidade era responsável por mediar as pesquisas realizadas bem como acompanhar o trabalho que era desenvolvido na escola. Já o professor/supervisor era responsável por nortear o trabalho dos graduandos e supervisionar o que era desenvolvido em sala de aula.

Para a realização das atividades no programa, eu e mais quatro alunos da universidade, não necessariamente do mesmo período, íamos para uma escola da rede estadual de ensino atuar como docentes. Tanto o grupo quanto a escola eram escolhidas por meio de um sorteio em uma reunião realizada pelo coordenador do programa na universidade.

Nessa reunião, a professora/supervisora da escola da qual fiz parte apontou que trabalharíamos com conteúdos de Literatura durante o ano. As atividades na escola eram desenvolvidas em dois dias da semana, para todas as turmas do $1^{\circ}$ e $2^{\circ}$ anos do ensino médio. As aulas que ministrávamos eram preparadas por todos os integrantes do grupo e todos tinham que participar. Além disso, uma vez por semana, nós (alunos pibidianos de diversas escolas do PIBID de Língua Portuguesa), professores/supervisores das escolas e o coordenador do PIBID de Língua Portuguesa, nos reuníamos para discutir sobre o trabalho que fazíamos em sala de aula e para discutirmos sobre algumas leituras propostas pelo coordenador.

Deve-se acrescentar que o PIBID foi idealizado pelo Ministério da Educação com o intuito de despertar mais interesse dos estudantes para as áreas de licenciatura e para uma melhor formação dos licenciandos. Com isso, o PIBID tornou-se um programa ímpar, já que nos permite refletir sobre diversos conteúdos, além de experienciar a docência por um viés mais crítico e reflexivo do contexto escolar, aperfeiçoando a prática docente.

Após essa contextualização, passo para o quadro teórico em que a pesquisa se 
sustenta. Na seção está presente o referencial teórico que permitiu fundamentar as análises e interpretações desta pesquisa. Está subdividido em Identidade e formação docente; Narra(R)tivas Autobiográficas: Contando histórias; Sistema de Avaliatividade.

\section{Identidade e formação docente}

A identidade de cada pessoa é constituída desde os seus primeiros contatos sociais, uma vez que o contexto no qual ela está inserida a influencia sobremaneira. Na infância, normalmente, assumimos características de nossos entes mais próximos, tendo em vista todo o processo de iniciação da fala, da linguagem, dos primeiros passos e escolhas. Após o período da infância, ao iniciarmos a vida estudantil, nossos colegas e o ambiente escolar tornam-se responsáveis pela transformação de nossa identidade, ocorrendo a todo momento e dependendo sempre do meio no qual estamos. Na vida adulta, essas mudanças são mais perceptíveis uma vez que assumimos diferentes papéis no dia a dia, seja de aluno ou seja de professor, em cada uma dessas funções assumimos posturas diferentes. Tendo isso em vista, notamos que a identidade em qualquer idade é contextual e dinâmica conforme apontam Reichmann e Romero (2019).

Ainda segundo as autoras a identidade é resultado das experiências e sentidos construídos pelo indivíduo em interações com outros. Além disso, os significados construídos pelos participantes na interação deve ser o foco da investigação quando o objetivo é entender identidade. Com isso, o uso das narrativas pode desencadear reflexões, que contribuem no entendimento da identidade, sendo um relevante recurso ao ser humano que faz uma retrospectiva de suas vivências ao narrar de si.

Nessa perspectiva, tem-se a identidade como resultado de nossas experiências, tanto pessoais quanto profissionais, variando de acordo com os ambientes nos quais estamos inseridos e nossas vivências. Dessarte, Hall (2006) defende que a identidade não se apresenta como considerável fixa, assumimos e transitamos por ela durante nossa vida, não somos fixos a uma só orientação identitária. Portanto, ela se constrói na relação, na comparação, na oposição, na aceitação do outro, ou seja, identidade é parte de um processo de compreensão de si e do outro, tendo natureza dinâmica e contextual.

Em perspectiva similar, segundo Vygotsky (1995), nos constituímos na relação com o outro. Nesse sentido, é coerente inferir que estamos a todo momento construindo e 
reconstruindo identidades e, na medida em que estamos em contato com os outros, nos reconstruímos e nos recriamos, já que essa relação traz diferentes aprendizagens e reflexões.

Sendo assim, o indivíduo, muitas vezes, inspira-se em outros, se reconhece em seus semelhantes e, no caso da formação docente, não é diferente. É comum nos depararmos com professores assumindo esse papel justamente porque tiveram influência de outros em suas vidas. Ademais, Barcelos (2016) e Block (2017) apontam que a identidade é resultado das diversas interações sociais que temos ao longo da vida, que compreendem, além da trajetória escolar, as culturas vivenciadas, bem como pessoas significativas que nos influenciaram e nos marcaram em nosso percurso. Não é, desta forma, um objeto que podemos possuir, mas algo que (re) construímos constantemente e vivemos. Como apresenta Nóvoa (2013, p.16):

A identidade não é algo adquirido, não é uma propriedade, não é um produto. A identidade é um lugar de lutas e conflitos, é um espaço de construção de maneiras de ser e de estar na profissão. Por isso, é mais adequado falar em processo identitário, realçando a mescla dinâmica que caracteriza a maneira que cada um sente e se diz professor.

Ressalta-se, portanto, que a identidade é dinâmica tendo a importância de que se conheça mais a fundo a trajetória dos professores bem como o quanto o professor deseja ressignificar suas ações. Com isso, considero o início da docência como uma importante fase no processo de construção da identidade do professor, momento no qual as marcas do estilo de como o docente trabalha e trabalhará, poderão, muitas vezes, influenciar em sua carreira (BLOCK, 2017). Tendo isso em vista, é válido ressaltar a importância das instituições de ensino, principalmente as formadoras de docentes, no que se refere às metodologias trabalhadas e o significado que estas têm na vida de muitos.

Nesse contexto, Romero (2010) destaca que a identidade profissional é construída sócio historicamente por meio das interações sociais, das formações, das experiências de vida adquiridas e da história do indivíduo, do contexto no qual ele está inserido, não se restringindo somente ao ambiente escolar e aos processos cognitivos. Assim, podemos dizer que o profissional não se constitui somente de conceitos, mas também de todas as experiências adquiridas durante sua vida.

Em acréscimo, Tardif (2014) afirma que o docente se constitui de diferentes maneiras e seus saberes advêm de sua história de vida, desde o seu nascimento, seu ambiente familiar e as relações com o outro e de sua carreira pessoal e profissional. Desse modo, a formação de 
uma identidade docente é um processo permanente e constante, a qual estamos recriando e reconstruindo a todo momento.

Segundo Nóvoa (2013), a formação de professores pode desempenhar um papel importante na configuração de uma nova personalidade docente. Posto isso, nossa identidade docente é de suma importância perante nossas práticas e reflexões educacionais, ou, até mesmo, quando influenciamos nossos alunos que, por meio de nossa prática, sentem-se motivados a tornarem-se professores.

Nessa perspectiva, o reconhecimento social, ou seja, a valorização do trabalho docente seja pela equipe pedagógica ou seja pela comunidade em geral e pelos valores da comunidade também é fator de satisfação profissional e que poderia levar à motivação de professores e, consequentemente, de alunos. E ter satisfação na prática contribui para se ter novas formas de identificação com a profissão, sendo assim, os fatores que levam o professor a alcançar suas metas e ter sucesso em determinadas situações do cotidiano escolar fortalecem a identidade docente que está sendo ressignificada por ele a todo o momento.

\section{Narrativas autobiográficas: contando histórias}

As experiências e vivências contadas por meio de narrativas dão vida e forma às ações do professor que, quando contadas por ele mesmo, como no caso das autobiografias, fornecem dados e relatos importantes para a exploração de seu trabalho. Dessa forma, o estudo e trabalho com essas experiências traz a voz do docente à tona. Em relação às narrativas, Miccoli (2014, p. 55) salienta que:

a análise de narrativas, orais ou escritas, mediadas pelo marco de referência, tem a experiência como unidade de análise. Essa análise privilegia, em um primeiro momento, um foco inicial que identifica o conteúdo das experiências e [é] complementada por outra, das relações entre as experiências identificadas. Na realidade, as experiências são imbricadas umas às outras, sendo separáveis, apenas, para fins de descrição, pois a análise relacional posterior permite compreender inter-relações e imbricamentos.

Tendo isso em vista, no trabalho com a escrita autobiográfica o professor tem liberdade para dar significado e sentido para a sua prática, conforme argumenta Silva (2014), em que ele afirma que é por meio da escrita reflexiva que o indivíduo é capaz de expressar 
seus pontos de vista, sentimentos, emoções e avaliações a respeito das experiências vivenciadas.

Nessa perspectiva, concordo com o autor quando ele expõe que esse tipo de escrita permite dar voz a nossa prática. No meu caso, dei voz a minha experiência por meio de uma autobiografia, já que as narrativas autobiográficas possibilitam a reflexão sobre o papel docente e, muitas vezes, permite que problemas enfrentados durante a docência sejam solucionados. Nesse sentido, as abordagens autobiográficas fazem reaparecer os sujeitos face às estruturas e aos sistemas, permitindo reflexões acerca da própria prática e mudanças de comportamentos.

E, sendo assim, o trabalho com as narrativas possibilita que nos vejamos sujeitos de nossa prática, podendo transformar nossas ações futuras, dando-nos um pouco mais humanidade frente ao sistema. Nessa perspectiva, Souza (2011, p.216) salienta que as pesquisas com autobiografias "assentam-se na hermenêutica crítica, face à interpretação do social e da valorização dos sentidos e significados construídos no contexto pelos sujeitos." Destacando, também, que a "intencionalidade, subjetividade, descrição, tradições, cotidiano e representações dos atores sociais são pontos fundamentais dessa abordagem de pesquisa." (SOUZA, 2011, p.216).

Outrossim, para Souza, (2016) é importante que se invista na formação dos professores, já que há a necessidade de se escutar a voz de um professor em processo inicial de formação [...] "no sentido de melhor entender o entrecruzamento do aprendizado constante e contínuo dos saberes, da identidade e da profissionalização, numa estreita relação com as subjetividades e singularidades das histórias de vida, através da abordagem biográfica”. (SOUZA, 2016, p. 25).

Dessa forma, as autobiografias, além de serem uma ferramenta de descobrimento e reflexão, permitem que os docentes narrem suas próprias histórias e se compreendam, mostrando-os suas experiências, emoções e crenças que interferem na construção de sua identidade (BARCELOS, 2016). Além disso, as narrativas permitem o desenvolvimento e crescimento do docente, uma vez que quem as escreve apresenta suas interações com diversas questões socioculturais, sua história de vida e contexto a qual ele pertence, seu convívio social, sua visão de mundo, suas atividades diárias dentre outras.

Nesse enfoque, a medida em que o docente se abre para o trabalho com autobiografias, ele se vê um profissional mais autônomo, ocupando uma posição de explorador e investigador 
de sua própria prática. A investigação do significado do ensino e de seu trabalho com o ensino é uma tarefa árdua, tonificante e reconstituinte (NÓVOA, 2013). As autobiografias permitem que o professor identifique um problema no seu modo de ensino e reflita sobre ele a fim de modificá-lo, transformando sua identidade docente. O exercício de escrita para o professor é catártico e terapêutico, utilizado como compreensão das relações e experiências com os outros, fazendo com que se possa melhorá-la e superar desafios.

Nóvoa (2013) e Barcelos (2016) também evidenciam a relevância da vida social do indivíduo para sua formação, sugerindo a reflexão sobre as histórias de vida em uma perspectiva autobiográfica para se compreender a relação do docente em formação com suas vivências. Aqui, enfatizo a influência que nossas relações, principalmente as que envolvem afetividade, tem sobre nós e sobre nossa prática. Dessa forma, Barcelos (2016) aponta que as relações que envolvem emoção atuam mais fortemente em nossa identidade e, consequentemente, são mais marcantes no processo de construção de narrativas autobiográficas.

Em síntese, Mello (2010) salienta que no trabalho com narrativas, o ponto central do estudo é a experiência pessoal ou profissional. "Ao partir de uma experiência vivida é possível revisitar experiências e construir conhecimento sobre as dimensões pessoal, profissional e social" (p. 185). Ainda, é possível analisar fatores como temporais, espaciais ou contextuais que estejam relacionadas a narrativa.

Infere-se, portanto, que diversos profissionais, além de registrarem os acontecimentos, transformam a sua forma de pensar e agir, o que leva a uma reorganização de ações, modificando-se através das suas reflexões enquanto escreve sobre si. Logo, o trabalho com autobiografia permite a reconstituição enquanto profissionais e sujeitos, recriando e trazendo à consciência a identidade docente.

Posteriormente, discorro sobre o sistema de Avaliatividade.

\section{Sistema de Avaliatividade}

A interação entre língua, a vida em comunidade, a forma de se relacionar com os outros e, principalmente, a linguagem em uso é o objeto de estudo da Linguística SistêmicoFuncional. O foco de seu estudo é a linguagem de forma geral e como a sociedade faz uso dessa linguagem. Nesse sentido, Martin e White (2005) apontam que a LSF analisa a 


\section{OO DEVIR EDUCAÇÃO}

ISSN: 2526-849X

materialidade do texto, oferecendo possibilidade às interpretações.

Nesse sentido, a obra de Martin e White The Language of Evaluation: Appraisal in English (2005) busca responder algumas inquietações acerca da linguagem, como:

de que maneira escritores e falantes instauram-se nos textos que produzem? Como são realizadas, linguisticamente, instâncias de envolvimento, atitudes, afeto, julgamento, apreciação, aprovação, desaprovação, entusiasmo e decepção em relação aos significados que se transmitem? De que modo, ainda, escritores e falantes constroem suas identidades nos textos? (LOPES e VIAN JR, 2007, p. 1)

Com base nesses questionamentos, os autores desenvolveram a teoria da Avaliatividade que "compreende atitudes positivas ou negativas que o escritor/falante possui em relação a algo.” (LOPES e VIAN JR, 2007, p. 1), atitudes, estas, que podem ser influenciadas pelas relações entre os indivíduos. Além do mais, Cabral (2011, p. 2) aponta que “é possível encontrar, no texto, elementos que comprovem sentimentos e valores 'postos' de uma comunidade, de modo a demonstrar emoções, gostos e avaliações normativas"

White (2004 apud ALMEIDA, 2018) aponta que o sistema de Avaliatividade é conceituado como uma abordagem específica que descreve, explora e explica a forma pela qual a língua é utilizada nos processos de avaliação, como exemplo, adotando uma postura, lidando com posicionamentos interpessoais e com os relacionamentos. Nesse sistema, é feito o estudo da forma pela qual os falantes e escritores fazem apontamentos e julgamentos sobre as pessoas e acontecimentos em geral.

Almeida (2018) explica que o termo Avaliatividade abrange toda a avaliação da linguagem, e que isso ocorre quando o falante/escritor expressa sua opinião sobre algo ou alguém. Ou seja, a linguagem é também uma forma de avaliar, de julgar, de opinar criticamente sobre o mundo, as coisas, as pessoas, os objetos e etc. Por meio desse sistema é possível categorizar e descrever os elementos léxico-gramaticais utilizados na avaliação realizada por meio da linguagem para a construção dos significados interpessoais.

Tendo isso em vista, deve-se pontuar que o sistema da Avaliatividade é voltado para a análise da escolha de estruturas semânticas, o sentido e significado que ele tem em determinados contextos, explicando o uso da língua em diversas situações seja ela para avaliar e julgar pessoas, objetos e/ou acontecimentos. Conforme aponta Cabral (2018 p. 233) "o Sistema de Avaliatividade está além do estrato da léxico-gramática, pois depende da 
assimilação ou não do interlocutor do discurso."

Nesse viés, o sistema de Avaliatividade é dividido em três subsistemas:

- Atitude;

- Engajamento;

- Gradação.

Ainda de acordo Almeida (2010, p. 39-40), "é importante esclarecer que esses três subsistemas estão relacionados entre si, uma vez que um sustenta e explica o outro"; isto é, a atitude abrange as avaliações, o engajamento contempla as fontes ou as origens da atitude; e a gradação focaliza a intensificação para mais ou menos das avaliações.

Para o desenvolvimento da análise linguística deste trabalho, demos ênfase ao subsistema de atitude (julgamento, afeto e apreciação) tendo em vista que ele diz respeito aos sentimentos de um modo geral, às emoções, julgamento de comportamento e avaliação de objetos e acontecimentos. Portanto, há uma relação direta com os objetivos deste estudo, especificados nas perguntas de pesquisa.

No subsistema de atitude, pode-se encontrar marcas de afeto, de julgamento ou de apreciação em produções orais ou escritas, de forma indireta, pressuposições assumidas ou não pelos envolvidos no discurso. A atitude, de acordo com (MARTIN, 2000 apud ALMEIDA, 2018), pode ser mais ou menos intensa ou mais ou menos ampliada de acordo com cada indivíduo. Ainda, é abordado que as atitudes ocupam lugar central no processo da Avaliatividade, elas revelam os tipos e os níveis em que a Avaliatividade é desenvolvida e expressa no discurso.

Como apontado anteriormente, o subsistema de atitude é dividido em três tipos: afeto, julgamento e apreciação, sendo que todos envolvem como nos posicionamos a nós mesmos, a outros ou ao mundo. O afeto, conforme apontam Martin e White (2005) contempla as emoções do sujeito, podendo estes sentimentos serem negativos ou positivos. Os subtipos relacionados são (in) felicidade, (in) segurança e (in) satisfação. Trago como exemplos: sintome feliz ou triste; calmo ou estressado; seguro ou inseguro.

Já o julgamento contempla a ética e a moral, usado para avaliar o comportamento das pessoas conforme aponta Martin (1995, p. 28 apud ALMEIDA, 2018, p. 187), sendo assim, uma análise normativa do comportamento humano baseado em regras ou convenções de comportamento. Ainda segundo o autor, a atitude de julgamento pode ser entendida como uma institucionalização do sentimento, ou seja, normas de comportamento que direcionam as 


\section{OO DEVIR EDUCAÇÃO}

ISSN: 2526-849X

pessoas para como devem ou não agir. Trago como exemplos: corajoso/covarde; poderoso/fraco; honesto/desonesto.

Além do mais Almeida (2018, p. 187) discorre que "o julgamento recontextualiza sentimentos no terreno de propostas sobre "como comportar-se”, a ética e a moralidade codifi cadas pela igreja e pelo Estado: Sanção Social e Estima Social”. A Sanção Social diz respeito às normas sociais ou religiosas e que se considera a propriedade e a veracidade. Segundo Martin e White (2005 apud FARENCENA, 2011), refere-se às normas estabelecidas socialmente, geralmente, são normas previstas por meio de legislação, preceitos e valores morais ou religiosos que podem constituir crime ou pecado, se infringidas.

Já a Estima Social refere-se às relações cotidianas, em termos de prestígio, admiração, decepção, status - observando a normalidade, a capacidade e a tenacidade. Conforme os autores Martin e White (2005 apud FARENCENA, 2011), a Estima Social diz respeito às relações do cotidiano entre as pessoas, dessa forma, não se caracteriza como norma institucional, isto significa que atitudes não implicam em crime ou pecado, mas estabelecem relações de prestígio (ou não), de admiração (decepção) ou status social.

A apreciação, última categoria da atitude, diz respeito ao modo como avaliamos coisas, objetos e situações/acontecimentos. Martin e White (2005, p. 37 apud ALMEIDA, 2010) afirmam que a apreciação diz respeito às avaliações sobre shows, filmes, livros, CDs, obras de arte, casas, prédios, parques, recitais, espetáculos ou performances de qualquer tipo, fenômenos da natureza, relacionamentos e qualidade de vida. Nessa perspectiva, a apreciação está relacionada com a afeição que temos a determinados objetos ou situação, por exemplo "isso me agrada/desagrada", "não quero/quero isso"

Além disso, conforme aponta Almeida (2018, p. 188), "a apreciação recontextualiza sentimentos no terreno de proposições, ou seja, sobre o valor das coisas, senso de beleza e valor que pode, por sua vez, ser codificado como medalhas, prêmios, etc. “ Ainda de acordo com a autora, a apreciação e o julgamento são as emoções que foram institucionalizadas para que pudéssemos viver em comunidade e sociedade.

Após apresentado o subsistema de atitude, parte do sistema de Avaliatividade, em que eu me embasei para analisar os dados da pesquisa, encaminho o trabalho prosseguindo para a metodologia escolhida.

\section{Metodologia}


É importante apontar que esta é uma pesquisa qualitativa, tendo em vista que, conforme discorre Minayo (2001, p. 14), “a pesquisa qualitativa trabalha com os significados, motivos, aspirações, crenças, valores e atitudes, o que corresponde a um espaço mais profundo das relações, dos processos e dos fenômenos que não podem ser reduzidos à operacionalização de variáveis”. Esse tipo de pesquisa era aplicado inicialmente em estudos de Antropologia e Sociologia, como contraponto à pesquisa quantitativa dominante e, atualmente, tem alargado seu campo de atuação a áreas como a Psicologia e a Educação.

Em consonância, Flick (2004) aponta que a pesquisa qualitativa é de particular relevância ao estudo das relações sociais devido à pluralização das esferas de vida e a pluralização das análises e resultados obtidos. Por isso, esse tipo de pesquisa possui grande relevância em estudos voltados a áreas sociais, uma vez que nessas áreas há um caráter subjetivo do objeto e envolvimentos emocionais.

Assim, para uma análise de dados de recortes de minha autobiografia, como aqui discuto, em que eu inseri minhas percepções acerca do PIBID, dificuldades, momentos que mais contribuíram para minha formação docente, a pesquisa qualitativa configura-se como de suma importância, tendo em vista que ela permite que o indivíduo se expresse livremente devido ao seu caráter subjetivo. Nesse sentido, ao expressar e rememorar episódios relevantes de meu percurso, posso refletir sobre os significados que eles podem ter tido em minha constituição profissional. Ademais, escrevi minha autobiografia durante mais ou menos três meses e tem aproximadamente 7 páginas, não só referentes ao PIBID, mas de fatos que me levaram a escolher a licenciatura em Letras e minha trajetória escolar.

Durante a análise de recortes de minha autobiografia, percebo como são apresentados conceitos como identidade, narrativas autobiográficas e formação de professores. Além disso, analiso de que forma o programa institucional de bolsa de iniciação à docência contribuiu para a construção da minha identidade e, para isso, baseei-me na perspectiva da Linguística Sistêmico-Funcional, pelo sistema da Avaliatividade, mais especificamente atitude (julgamento, afeto e apreciação). (MARTIN; WHITE, 2005; ALMEIDA, 2010, 2018).

Portanto, a escolha do subsistema de atitude (MARTIN; WHITE, 2005; ALMEIDA, 2010, 2018) ocorre, uma vez que os recursos semântico e linguísticos presentes no corpus expressam sentimentos e emoções, julgamentos de caráter e avaliações (ALMEIDA, 2010, 2018). A atitude é um subsistema que permite identificar vários pontos de vista 
complementares que ajudam a interpretar a língua em uso, possibilitando em uma construção teórica e descritiva sobre o como e o porquê do uso de determinadas expressões e léxicos em determinados contextos.

Definido, então, o corpus de análise, a partir das seguintes perguntas, categorizei os recortes de minha autobiografia:

1. Quais os pontos de minha experiência formativa no PIBID considerei mais relevantes?

2. Quais os desafios encontrados durante a participação no PIBID?

Posteriormente, por meio da Avaliatividade (MARTIN; WHITE, 2005, ALMEIDA, 2010, 2018), analisei, dando ênfase para atitude (julgamento, afeto e apreciação), a seguinte pergunta:

3. Como signifiquei minhas experiências e desafios de acordo com o subsistema de atitude (julgamento, afeto e apreciação)?

Antes de iniciar a discussão dos dados, explorei minha autobiografia e selecionei momentos que considerei mais importantes para a construção de minha identidade docente e formação docente norteado pelas minhas perguntas de pesquisa. Após isso, identifiquei as principais marcas linguísticas presentes no texto, com base no Sistema de Avaliatividade, com a finalidade de validar as interpretações feitas embasadas nos conceitos teóricos que apresentei no quadro teórico desta pesquisa.

Após essa breve explicação, parto para a discussão dos dados.

\section{Discussão}

Após a classificação dos dados com recortes de minha autobiografia, eu analisei como signifiquei minhas aprendizagens de acordo com as teorias de identidade docente, formação de professores e de atitude (julgamento, afeto e apreciação).

4.1 - Nesta seção, com os recortes 1, 2, e 3 busco responder as perguntas de pesquisa 1 e 3.

\section{Recorte 1}

"Em um dos primeiros encontros que tive com o grupo, ficou decidido quais os conteúdos 
de Literatura que iríamos abordar em sala de aula. Cada membro ficava responsável por alguma tarefa e íamos revezando; um, ficava responsável por montar os slides que utilizaríamos na aula; outro, escolheria o vídeo que levaríamos; dois, pesquisavam o conteúdo; e um preparava as discussões que teríamos. Por várias vezes eu ficava com a parte de pesquisar os conteúdos que iríamos trabalhar com os alunos, já que não sabia muito sobre a disciplina de Literatura e porque me dava bem com meu outro colega que também ficava responsável pela pesquisa. Quando chegava na hora da aula, sabia bem o que havíamos preparados, no entanto, muitas perguntas, dúvidas e apontamentos dos alunos faziam com que eu sempre aprendesse mais. Eu era professora e aluna ao mesmo tempo naquele ambiente, já que aprendia com os outros colegas e alunos, aprendia estudando para dar as aulas e gostava disso."

Por meio desse recorte, percebo que "transito" por diversos papéis e exerço diferentes funções enquanto pibidiana. Em cada contexto eu assumo uma identidade diferente o que fica nítido ao analisar minha autobiografia. Ao destacar o trecho "Eu era professora e aluna ao mesmo tempo" vejo duas identidades que se envolvem e adequam àquele momento, ou seja assumo identidades diferentes, relacionadas ao eu pessoal e profissional, relevantes para aquele contexto. (BARCELOS, 2016).

Além disso, Barcelos (2016) ainda destaca que identidade é influenciada pelas experiências vivenciadas. Nesse sentido, se, atualmente, eu gosto de conteúdos relacionados a Literatura, é devido ao fato de ter experienciado esses conteúdos em um ambiente e momento que despertaram minhas emoções, pelo contato que eu tive com colegas que gostavam da disciplina e devido a autonomia que a supervisora nos dava para abordar os conteúdos da forma que quiséssemos.

Ademais, podemos perceber a satisfação que eu sentia ao aprender com a participação no programa, consolidando-se como um sentimento de atitude - afeto, e, acordo com Martin (2000 apud ALMEIDA, 2018), o afeto contempla as emoções que temos e demonstramos de alguma forma em relatos. Dessa forma, ao passo que eu inseri a expressão "gostava disso" (aprender com os outros colegas e alunos e aprender estudando para dar as aulas) explicitamente demonstrei o quanto aquilo era importante para mim. Além do mais, no excerto "aprendia com os outros colegas e alunos" fica evidente a conceituação de Vygotski (1995), quando ele afirma que o indivíduo é um ser social que se desenvolve de acordo com o contexto em que está inserido e na interação com os outros. 
Outrossim, quando aponto que me dava bem com meu outro colega o afeto é presente na condição do sentimento de gostar de outra pessoa, ter uma boa relação com ela. Tendo isso em vista, as avaliações por afeto nos trechos ocorrem no sentido de expressar as minhas reações emocionais nos fatos apresentados e explorados.

\section{Recorte 2}

"Me senti muito sortuda com a escolha do grupo, do tema e da escola que trabalharia no PIBID, porque tínhamos autonomia no modo de prepararmos a aula e de lecionarmos, inserindo o lúdico e "rompendo" com o tradicional, tentando de diversas formas fazer com que os alunos se interessassem pelo conteúdo abordado e pela Literatura. Depois de pouco tempo trabalhando Literatura, pude me ver totalmente envolvida com a disciplina, como um caso de amor descoberto. Não só eu, mas também a maioria dos alunos da escola, os quais não tinham a mínima vontade de aprender e estudar os conteúdos desta matéria."

A identidade docente se constrói na relação com o outro, na comparação, na aceitação do outro, ou seja, a identidade é um processo de compreensão de si e do outro conforme acentua Barcelos (2016). Nesse viés, o PIBID teve suma importância para a ressignificação de minha identidade docente, já que o contato com os outros colegas, alunos e professores fizeram com que eu me envolvesse com a disciplina e desenvolvesse afeição por ela. Logo, configurando-se em afeto quando aponto que Depois de pouco tempo trabalhando com Literatura, pude me ver totalmente envolvida com a disciplina, como um caso de amor descoberto. Não só eu, como também a maioria dos alunos da escola.

É por meio do afeto que o falante/escritor revela suas emoções ou descreve as emoções de outros, e podemos entender como os sentimentos e emoções se apresentam, avaliações ou como o produtor textual se sente em relação às coisas, aos objetos, às pessoas, aos comportamentos e outros, como sugere Martin (2000).

Além disso, quando aponto o trecho porque tínhamos autonomia no modo de prepararmos a aula e de lecionarmos, inserindo o lúdico e "rompendo" com o tradicional, percebo que este configura-se em um julgamento, já que essa subcategoria traduz a maneira pela qual as pessoas fazem avaliações sobre moralidade, legalidade, capacidade, normalidade, sempre determinados pela cultura na qual vivem e pelas experiências, pretensões e crenças 
individuais moldadas por uma cultura particular e uma situação ideológica (ALMEIDA, 2018). Dessa maneira, caracterizo o ato de ter autonomia e de romper com o tradicional como estima social, referindo-se a padrões sociais de comportamento, julgando se o comportamento é comum ou incomum, se foge ou se está de acordo com a normalidade do que é estimado socialmente.

\section{Recorte 3}

"O PIBID foi, sem dúvidas, a melhor experiência profissional e com a docência que já tive até hoje. Foi por meio desse programa que consegui enxergar as diversas possibilidades de ser um professor, de que tipo de professor eu gostaria de ser. Eu pude sentir que estava fazendo a diferença na vida de vários adolescentes e isso foi extremamente importante e gratificante em minha vida. E, além disso, minhas aprendizagens com a participação no programa se deram, não só cognitivamente, por meio dos conteúdos que lecionava, mas também pessoalmente, com as experiências dos meus colegas, professores e, principalmente, com os alunos os quais assistiam nossas aulas. Aprendi que um professor trabalha muito além dos conteúdos programados, já que parávamos bastante as aulas para falarmos sobre faculdade, experiências, dificuldades vividas. Como em uma dessas aulas, em que um aluno se emocionou ao dizer que não sabia que a UFLA era pública e que ele poderia cursar algo que ele gostasse gratuitamente.“

Quando refletimos sobre nossa prática docente é comum lembrarmos de situações marcantes que ocorreram dentro da sala de aula que não estão diretamente relacionadas aos conteúdos que trabalhamos. Essas situações nos mostram que a nossa identidade profissional se transforma e se constrói por meio de nossas interações sociais, experiências de vida (ROMERO, 2010). Nesse sentido, quando eu digo que "Minhas aprendizagens com a participação no PIBID se deram, não só cognitivamente, por meio dos conteúdos que lecionava, mas também pessoalmente, com as experiências dos meus colegas, professores e, principalmente, com os alunos os quais assistiam nossas aulas.", reforço o quanto as relações sociais são importantes para nossa formação docente, não se restringindo somente aos processos cognitivos, sendo esse um sentimento de atitude - afeto, devido a satisfação com as aprendizagens que eu estava obtendo.

Nesse contexto, Nóvoa (2013) e Gatti (2013) destacam que não nos constituímos apenas de conceitos cognitivos que aprendemos nos livros, em cursos e na faculdade, e nem 
de conteúdos preestabelecidos como física, química e matemática, mas também das interações realizadas durante nosso processo de formação. Ademais, Tardif (2014) afirma que o docente se constitui de diferentes maneiras e destaca a importância das relações com o outro para sua formação.

Em relação à LSF, pode-se categorizar o trecho "Aprendi que um professor trabalha muito além dos conteúdos programados." como atitude - julgamento, já que antes de iniciar minha prática docente eu acreditava que os conhecimentos cognitivos do professor eram suficientes para ministrar uma aula com sucesso. Assim, conforme afirma Martin (1995, p. 28 apud ALMEIDA, 2018), a subcategoria de atitude serve para avaliar o comportamento das pessoas e eu, no recorte, avaliei o comportamento do professor antes de ser uma professora.

4.2 - Nesta seção, com os recortes 4 e 5, respondo as perguntas de pesquisa 2 e

3.

\section{Recorte 4}

"Na primeira reunião que teve do PIBID de Português ficou decidido em qual grupo cada membro do programa ficaria e qual escola da cidade ele desenvolveria as atividades. Estavam presentes as supervisoras de cada escola, o coordenador do programa na universidade e os alunos pibidianos. Formando grupos de 5 membros, cada aluno um foi designado a uma escola e sua respectiva supervisora. A supervisora do grupo, do qual eu fui sorteada para participar, sugeriu que fosse trabalhado com conteúdos de Literatura. Como eu não estava presente nesta reunião, não pude intervir e nem opinar sobre e, quando descobri que trabalharíamos com Literatura, eu levei um choque porque não gostava e não sabia nada sobre a disciplina."

Ao relatar que "não gostava e não sabia nada sobre a disciplina", mesmo sem ter tido a oportunidade de trabalhar com ela, evidencio o pré conceito que a tratei pelo fato de ser algo novo e ter medo do "novo", sendo isso, para mim, um dilema, entendido por Zabalza (2004), como um conjunto de situações conflitantes que se apresentam ao docente no desenvolvimento de sua atividade profissional. Esses dilemas podem atormentar psicologicamente de acordo com o grau de importância que o sujeito dá a ele, no meu caso, trabalhar com a disciplina de Literatura seria meu conflito. No entanto, quando enfrentei esse dilema, encarando as aulas e estudando para fazer um bom trabalho, percebi a importância do 


\section{OO DEVIR EDUCAÇÃO}

ISSN: 2526-849X

de tal disciplina e que eu poderia, sim, dominá-la e entendê-la.

Linguisticamente, ao analisar o recorte anterior, percebo que se configura em atitude apreciação, tendo em vista que avaliei a disciplina de Literatura. A apreciação na Avaliatividade exerce a função de caracterizar e avaliar coisas, objetos e fenômenos. Conforme destaca Almeida (2018), a apreciação abrange as reações dos falantes e as avaliações da realidade, sendo essas reações individuais, já que ela corresponde às reações que as ações, coisas, objetos e fenômenos provocam nas pessoas. Assim, quando digo que "não gostava da disciplina" estava reagindo sobre algo, que é a disciplina de Literatura devido às ações e sentimentos que ela já havia causado em mim. Além disso, Ao apontar que "levei um choque", percebo um julgamento negativo de estima social, tendo em vista que se trata de uma relação do cotidiano que indica decepção com algo ou alguma coisa. Está dentro da perspectiva da normalidade, não sendo, neste caso, algo não normal.

\section{Recorte 5}

"Planejamos mais uma aula para tratarmos sobre Barroco, como o conteúdo era extenso, dividimos-o em duas aulas. Era um conteúdo que todos do grupo gostavam de falar, levamos poemas, vídeos, imagens que pudesse chamar a atenção dos alunos e que eles pudessem participar mais. No entanto, poucos alunos da turma x participavam, achávamos que eles não prestavam atenção e não tinham interesse no conteúdo que lecionávamos, eram muito apáticos e nada que fazíamos os agradavam. Com isso, acabei me frustrando algumas vezes pelo fato da aula não ter saído como esperávamos, pelo fato dos alunos não absorverem o conteúdo. Isso foi um dos pontos que mais trabalhei em mim durante o projeto, criar pouca expectativa em cima do que poderia ocorrer."

Minha participação no PIBID foi um dos primeiros contatos que eu tive com sala de aula, com o ato de lecionar, sendo esse um processo de formação inicial. Nesse ínterim, Freudenberger e Pereira (2012, P. 115) afirmam que analisar e participar desse processo é também desafiador, exigindo do docente o desenvolvimento de novos instrumentos e novas metodologias para tal. Dessa forma, no momento em que eu relato que "Acabei me frustrando algumas vezes pelo fato da aula não ter saído como esperávamos, pelo fato dos alunos não absorverem o conteúdo", vi a necessidade de mudança em minha prática docente, mudança na metodologia para o trabalho com a disciplina, sendo um processo que exigiu muito de 
$\operatorname{mim}$.

Nesse sentido, pude, então, reconstituir minha identidade docente tendo em vista que foi um momento que envolveu muita emoção para mim (BARCELOS, 2016), pois nesse momento, percebi que as aulas nem sempre acontecerão da forma com que planejo e que, quando se lida com pessoas, os resultados podem ser diversos. Além disso, Souza (2016) aponta que identidade profissional não é dada, mas construída nas relações de trabalho.

De acordo com o subtópico da Avaliatividade, atitude, quando eu digo que "Acabei me frustrando..." há um sentimento de frustração com a expectativa que criei em cima de um ato (o de ensinar e os alunos não aprenderem), logo, sendo uma insatisfação com meu próprio trabalho. Sendo assim, esse recorte pode ser classificado como atitude - afeto - porque é uma avaliação pautada nos meus sentimentos e emoções em relação às expectativas criadas por mim, sendo insatisfatório para mim. E, também, há também um julgamento de Estima Social indicativo de decepção, contemplando a capacidade, nesse caso espera-se que as aulas sempre saiam do modo como o professor planeja, o que nem sempre é possível.

\section{Considerações Finais}

Durante o processo de escrita de minha autobiografia, focada nas experiências que contribuíram para a minha construção como professora, deparei-me com a percepção de que o PIBID exerceu grande influência na formação de minha identidade docente, bem como em aprendizagens pessoais. Nesse sentido, entendo que os desafios enfrentados e as conquistas obtidas durante os dois anos em que participei, foram de suma importância para a construção do meu "eu" profissional atual.

Por meio do PIBID pude enxergar as diversas formas de exercer a prática docente e que tipo de professora eu gostaria de ser, uma vez que ele me permitiu uma prática mais reflexiva sobre minhas ações e papéis no ambiente escolar. Desse modo, pude sentir que estava fazendo a diferença na vida de vários adolescentes, contribuindo para a reconstrução da identidade deles - o que foi extremamente importante e gratificante em minha vida - assim como eles contribuíram para a formação de minha identidade docente.

Ademais, as narrativas autobiográficas são instrumentos essenciais que auxiliam na reflexão sobre o contexto que os docentes e futuros docentes vivenciam nas experiências nos 
ambientes de ensino e para conseguir diagnosticar desafios e percepções relevantes que podem estar implícitos e, de alguma forma, interferem na sua posição como profissional.

Dessa forma, pode-se notar, por meio de recortes de minha autobiografia, o impacto que esse programa exerceu sobre mim, trazendo alterações em minha identidade como docente de língua portuguesa. A experiência no PIBID atuou como uma possibilidade de aproximação universidade-escola e de vivência real da prática pedagógica.

\section{Referências}

ALMEIDA, Fabíola Aparecida Sartin Dutra Parreira. Avaliação na linguagem: os elementos de atitude no discurso do professor: um exercício em análise do discurso sistêmicofuncional. São Paulo: Pedro \& João, 2010.

ALMEIDA, Fabíola Aparecida Sartin Dutra Parreira. Comentários em blogs de professores de inglês: uma análise do sistema de Avaliatividade. DELTA: Documentação e Estudos em Linguística Teórica e Aplicada, v. 34, n. 1, 2018.

BARCELOS, Ana Maria Ferreira. Identities as emotioning and believing. Reflections on Language Teacher Identity Research, 2016.

BLOCK, David. Journey to the centre of language teacher identity. 2017. Disponível em: https://www.academia.edu/RegisterToDownload\#BulkDownload. Acesso em: 30 de setembro de 2019.

CABRAL, Sara Regina Scotta. Teoria da avaliatividade: estudos introdutórios. Disponível em: . Acesso em: 01 abr. 2011.

CABRAL, Sara Regina Scotta. FREITAS, Jéssica Cantele de. Avaliatividade: Marcas Linguísticas em exemplares do gênero exposição. In.: CABRAL, Sara Regina Scotta. BARBARA, Leila. (org.) Estudos Sistêmicos Funcionais no Âmbito do Projeto Sal. Rio Grande do Sul. PPGL, 2018.

FARENCENA, Gessélda Somavilla. As representações nas fábulas O Lobo e o Cordeiro a partir dos recursos de avaliatividade. Disponível em: . Acesso em: 04 abr. 2011.

FLICK. Uwe. Introdução à pesquisa qualitativa. Tradução: Joice Elias Costa. 3-ed.-Porto Alegre. Artmed. 2004.

FREUDENBERGER,Francieli Martiny; PEREIRA, Regina Celi Mendes. Descrição e Análise do Trabalho Docente em Relatórios de Estágio Produzidos por Professores em Formação Inicial: Possibilidades e Contradições. Rádio (online), v.6, 2012.

GATTI, Bernadete Angelina; BARRETO, Elba Siqueira de Sá (Coord.). Professores do Brasil: impasses e desafios. Brasília, DF: UNESCO, 2009. Disponível em: <Disponível 
em:http://unesdoc.unesco.org/images/0018/001846/184682por.pdf $>$. Acesso em: 20 julho. 2019.

GATTI, Bernadete Angelina. Educação, escola e formação de professores: políticas e impasses. Educar em Revista. Curitiba, Brasil, n. 50, p. 51-67, out./dez. 2013.

HALL, Stuart. A identidade cultural na pós-modernidade. TupyKurumin, 2006.

LOPES, Rodrigo Esteves de Lima; VIAN JR., Orlando. The language of evaluation: appraisal in english. DELTA - Revista de Documentação de Estudos em Linguística Teórica e Aplicada, v. 23, n. 2, São Paulo, 2007.

MARTIN, James. Beyond Exchange: Appraisal System in English. In: HUNSTON, Susan \& THOMPSON, Geoff. Evaluation in text: authorial stance and the construction of discourse. Oxford: Oxford University Press, 2000.

MARTIN, James; WHITE, Peter. The language of evaluation: appraisal in English. New York: Palgrave, 2005.

MELLO, Dilma Maria de. Pesquisa Narrativa: Fenômeno Estudado e Método de Pesquisa. In.: ROMERO, Tania Regina de Souza (org.). Autobiografias na (re)constituição de identidades de professores de línguas: o olhar crítico-reflexivo. Campinas: Pontes, 2010.

MICCOLI, Laura Stella. A evolução da pesquisa experiencial - uma trajetória colaborativa. In: MICCOLI, Laura Stella. (org.) Pesquisa com foco na Experiência: uma teoria em evolução. Campinas, SP: Pontes Editores, 2014.

MINAYO, Maria Cecília. de Souza (Org.). Pesquisa Social: teoria, método e criatividade. 19.ed. Petrópolis: Vozes, 2001.

NÓVOA, Antonio (Org.). Vidas de professores. $2^{\circ}$ ed. Portugal: Porto Ed., 2013.

REICHMANN, Carla Lynn.; ROMERO, Tania Regina de Souza. Language teachers' narratives and professional self-making. DELTA: Documentação e Estudos em Linguística Teórica e Aplicada, v. 35, n. 3, 2019.

ROMERO, Tania Regina de Souza. Autobiografias de Professores de Inglês: o entretecer de memória e narrativa na constituição da identidade profissional. In: Maria Antonieta Alba Celani (org.) Reflexões e Ações (Trans)Formadoras no Ensino-Aprendizagem de Inglês. Campinas: Mercado de Letras, 2010.

ROMERO, Tania Regina de Souza. Diálogos (im)pertinentes entre formação de professores e aprendizagem de línguas [livro eletrônico] /organização de Elaine Mateus, Juliana Reichert Assunção Tonelli. - São Paulo : Blucher, 2017.

SILVA, Wagner Rodrigues. Reflexão pela escrita no estágio supervisionado da licenciatura: pesquisa em linguística aplicada. Campinas: Pontes, 2014. 
SOUZA, Elizeu Clementino de. Territórios das escritas do eu: pensar a profissão - narrar a vida. Educação, Porto Alegre, v. 34, n. 2, 2011.

SOUZA, Elizeu Clementino de. Profissionalização, fabricação de identidade e trabalho docente: Alguns apontamentos teóricos. Construções Identitárias de Professores de Línguas. Campinas. Ed. Pontes. 2016.

TARDIF, Maurice. Saberes docentes e formação profissional. 17. ed. Petrópolis, RJ: Vozes, 2014.

VYGOTSKY, Lev Semyonovich. Pensamento e Linguagem. São Paulo: Martins Fontes. 1995.

ZABALZA, Miguel. Diários de aula: um instrumento de pesquisa e desenvolvimento profissional. Porto Alegre: Artmed, 2004. 